

\title{
AÇÕES MISSIONÁRIAS ENTRE CULTURAS DIFERENTES SOB O OLHAR DA FENOMENOLOGIA
}

\section{MISSIONARY ACTIONS BETWEEN DIFFERENT CULTURES UNDER THE VIEW OF PHENOMENOLOGY}

\section{Mariluce Emerim de Melo August ${ }^{1}$}

RESUMO

Ações missionárias entre culturas diferentes sob o olhar da fenomenologia se apresentam como objeto de estudo nesta pesquisa de base bibliográfica. Através da comissão de Jesus em Mateus 28 , as ações missionárias cristãs tendem a marcar presença em outras culturas para proclamar as boas novas do Evangelho de Cristo. Formas de abordagem de outras culturas por missionários para transmissão das boas novas do evangelho têm sido questionadas por alguns estudiosos de missões. A hipótese para a presente pesquisa é de que os princípios da fenomenologia podem servir como método de compreensão de outras culturas, melhorando assim a comunicação entre culturas diferentes e aumentando as possibilidades de aceitação. O método fenomenológico é abordado principalmente na compreensão da filósofa italiana, Ângela Ales Bello, a partir dos manuscritos de Edmund Husserl (1859-1938). Conclui-se que os princípios da fenomenologia podem orientar, com vantagens, as pesquisas no campo da Teologia, como acontece em outras áreas das ciências humanas.

Palavras-chave: Fenomenologia. Diferentes culturas. Missões Transculturais.

\section{ABSTRACT}

Missionary actions among different cultures under the perspective of phenomenology are presented as an object of study in this bibliographical research. Through the commission of Jesus in Matthew 28, Christianity tends to be present in other cultures to proclaim the good news of the gospel of Christ. Approach to forms of other cultures by missionaries to broadcast the news of the

${ }^{1}$ Doutora e Mestre em Teologia pela PUCPR. Especialista em Ministério Pastoral e Bacharel em Teologia pela Faculdade Fidelis. Arquiteta e Urbanista pela UFSC. Discente do curso de Bacharelado em Teologia da Faculdade Fidelis.marilucearq@gmail.com. 
gospel good have been questioned by some scholars missions. The hypothesis for this study is that the principles of phenomenology can serve as a method of understanding of other cultures, thus improving the communication between different cultures and increasing the acceptance of possibilities. The phenomenological method is discussed mainly in understanding the Italian philosopher, Angela Ales Bello, from the manuscripts of Edmund Husserl (1859-1938). It concludes that the principles of phenomenology can guide with benefits, research in the field of theology, as in other areas of the human sciences.

Keywords: Phenomenology. Different Cultures. Transcultural Missions.

\section{INTRODUÇÃO}

O texto bíblico de Mateus 28 e outros têm estimulado a propagação do evangelho por todo o mundo, ensinando, discipulando e batizando. É considerada a tarefa missionária de levar as boas novas do evangelho a todas as pessoas, de todas as culturas e de todos os lugares do mundo. $\mathrm{O}$ texto diz: "Portanto, vão e façam discípulos de todas as nações, batizando-os em nome do Pai e do Filho e do Espírito Santo, ensinando-os a obedecer a tudo o que eu lhes ordenei" (Mt $28.19,20)^{2}$.

Vários estudiosos e pesquisadores de missões, e também missionários têm avaliado os métodos correntes de abordagem e sua aplicabilidade nas missões interculturais. A obra "Tropeços na Ação Missionária”, de Jarbas Ferreira da Silva, levanta questões que são conhecidas de diversas agências missionárias sobre a abordagem no campo missionário e o modo como acontece o encontro de culturas diferentes, a do povo a ser alcançado e a do missionário ou da missionária. Para o autor, o preparo transcultural é de grande importância e deve estimular uma desestruturação sadia dos missionários no que tange ao seu invólucro cultural, a fim de abrir a mente para o diferente, para os valores e ética da nova cultura. Oliveira (2008, p. 24) também concorda e acrescenta que o preparo deve ser no sentido de assumir, ainda, uma postura responsável no relacionamento com o povo que se deseja alcançar com o evangelho.

O que acontece é que alguns modelos de abordagem são vistos em forma de crítica cultural e tende a comprometer a divulgação do Evangelho. Em algumas situações, o Evangelho não encontra espaço de aceitação pela forma como é anunciado por não ser compreendido adequadamente. E é exatamente isto que alguns estudiosos de missões transculturais, e porque não dizer antropólogos da religião, estão sempre avaliando e debatendo. O que parece que falta nos vários estudos publicados sobre o tema é a utilização de métodos adequados de pesquisa com

$\overline{{ }^{2} \text { Todos os textos bíblicos deste texto, }}$ quando não especificado, foram extraídos da Bíblia online - Nova Versão Internacional. 
maior valor científico. No campo da ciência das religiões e em outras áreas de estudo das ciências humanas, a abordagem fenomenológica tem sido abordada na análise de dados. E a fenomenologia como método poderia ser mais conhecida e utilizada nas pesquisas de campo de atuação de missões transculturais evangélicas. O "método fenomenológico", tendo nascido da filosofia, encontra no campo da investigação apontado pela antropologia cultural, uma possibilidade surpreendente de confirmação da sua validade como instrumento de compreensão de culturas diferentes e, por conseguinte, a transculturalidade (ALES BELLO, 1998, p. 68).

Assim, o objetivo deste estudo é verificar, através de pesquisa bibliográfica, o potencial da fenomenologia para análise e compreensão de diferentes culturas e sua aplicabilidade, como possibilidade, em missões transculturais. Para alcançar o objetivo geral, se pretende esclarecer o que é a fenomenologia na forma como vem sendo compreendida desde seu sistematizador Edmund Husserl (1859-1938). E, através das premissas do método fenomenológico, compreender as diversas ações de alguns estudiosos de missões transculturais no meio evangélico.

Acredita-se que a adequada compreensão da fenomenologia pode agregar valor para a comunidade acadêmica, especialmente no campo da Teologia. Isto se daria pela abrangência do método e suas possibilidades em diversos saberes como a filosofia, ciências sociais, psicologia, história das religiões, entre outras. Propiciaria também novas possibilidades de abordagem inclusive na sociedade de origem dos missionários, quando se trata de ações missionárias locais, no sentido de compreender também sua própria cultura.

A justificativa pessoal para a escolha deste tema consiste num antigo interesse da pesquisadora por missões interculturais, onde já fez algumas incursões no passado. Em relação à fenomenologia, a pesquisadora tem adentrado nesta área nas pesquisas que vêm realizando sobre a atuação dos missionários solteiros em culturas diferentes, e tem estudado o método fenomenológico como possibilidade de compreensão dos fenômenos que são seu objeto de estudo. Além disso, a pesquisadora desenvolveu sua tese de doutorado sob abordagem fenomenológica para a análise de dados da pesquisa de campo na temática da experiência de missionárias solteiras em missões na África, tendo comprovado a eficácia do método.

Este texto está sistematizado com os seguintes tópicos: Aspectos filosóficos da Fenomenologia; A arqueologia fenomenológica e a antropologia cultural; O papel da religião para a cultura; A teologia e a abordagem fenomenológica; As ações missionárias, a fenomenologia e a ética do respeito. 


\section{ASPECTOS FILOSÓFICOS DA FENOMENOLOGIA}

De acordo com o filósofo francês Paul Ricouer (1913-2005), em sua obra "Na escola fenomenológica", a fenomenologia nasceu de uma crise de ceticismo, "posterior à descoberta da intencionalidade e relativa à própria possibilidade da intencionalidade, isto é, finalmente, de sua referência a uma transcendência" (RICOUER, 2009, p. 13). Ele diz "finalmente" porque vários estudos filosóficos na época não destinavam espaço e nem sentido para a existência de Deus. E pela fenomenologia defendida por Husserl, o sentido da religiosidade e fé como experiência pessoal não pode ser negada.

Ricouer afirma que a obra "Meditações Cartesianas" de Edmund Husserl tem a intenção de situar na história da filosofia o motivo transcendental da fenomenologia, lentamente conquistado a partir de 1905. A obra "Krisis" (1935) de Husserl, "vê na reflexão transcendental um modo de filosofar que tem sua própria história e atravessa a história da 'ingenuidade', isso é, a história das ciências, das técnicas e das filosofias objetivistas que permaneceram fascinadas pelo naturalismo científico" (RICOUER, 2009, p. 161).

Além de alguns livros publicados, 30.000 páginas de manuscritos de anotações de aula, em alemão, do professor, filósofo e matemático tcheco, Edmund Husserl, luterano de origem judaica, tem sido traduzido após sua morte, especialmente pela filósofa italiana Angela Ales Bello. Esses manuscritos têm sido estudados por vários seguidores de suas ideias, a fim de melhor compreender o método fenomenológico sistematizado por ele no início do século XX, de acordo com Cerbone (2013, p. 28).

Segundo Ricouer (2009, p. 7), Husserl não é toda a fenomenologia, embora seja de certa maneira o seu nó. A fenomenologia tem uma memória que a insere no passado da filosofia ocidental. O autor lembra que Hegel, na verdade, “já compreendera a fenomenologia como uma inspeção ampla de todas as variedades da experiência humana (não apenas epistemológica, mas também ética, política, religiosa, estética e cotidiana)." Enfim, Ricouer acredita que a fenomenologia é a soma das variações do próprio Husserl e, de modo particular, a soma das descrições propriamente fenomenológicas e das interpretações filosóficas pelas quais reflete e sistematiza o método.

Ales Bello, autora da obra "Culturas e religiões - uma leitura fenomenológica", investiga a fenomenologia na fonte, direto de seu sistematizador, Edmund Husserl e de uma discípula dele, a judia, convertida ao catolicismo, Edith Stein. Com base nos escritos de Husserl em sua corrente filosófica, Ales Bello afirma que a investigação fenomenológica é orientada pela percepção do 
"sentido", destacando a importância e a centralidade daquilo que se manifesta. Ao mesmo tempo, faz a leitura dos fenômenos culturais e religiosos, segundo a origem das várias maneiras de pensar o mundo nas "experiências vivenciais" (ALES BELLO, 1998, p. 12).

É possível discernir três ramos mestres da fenomenologia, de acordo com Ricouer. Um é a fenomenologia de Husserl, outro é a fenomenologia crítica esboçada por Kant que orienta a investigação do fenômeno sobre uma posição absoluta de realidade que limita as pretensões do fenômeno a se dar como o absoluto. E, ainda, um terceiro ramo se refere à fenomenologia do espírito, como orienta Hegel (RICOUER, 2009, p. 150).

Ales Bello (1998, p. 13) afirma que a eficácia da fenomenologia não pode ser testada a não ser na pesquisa de campo e na análise concreta dos fenômenos que despertam a atenção. E, tanto a cultura quanto a religião, podem ser submetidas a uma investigação visando captar as suas estruturas essenciais e estabelecer as suas relações. Nesse sentido, a compreensão e o estabelecimento dessas relações são de grande importância para uma missão religiosa no encontro de duas culturas diferentes.

A fenomenologia, em suma, é a ciência das essências, diferente da ciência dos fatos (positivismo) e dos aspectos naturais (naturalismo), e tem como objetivo chegar aos significados constituídos na subjetividade, segundo Goto. Ela também conduz às vivências dos fenômenos, além de conduzir à subjetividade transcendental, podendo ser designada como "ciência à priori, cuja finalidade principal é descrever os fundamentos da filosofia e da ciência para restabelecer o sentido delas". Dessa forma, busca reformulá-las metodologicamente (GOTO, 2008, p. 81).

Conforme Ales Bello (1998, p. 14), a fenomenologia torna possível uma verdadeira comparação das expressões culturais ocidentais com outras diferentes através de uma leitura interior. Configura-se como uma arqueologia das experiências vivenciais, cujo aprofundamento através da análise concreta permite captar de uma forma mais precisa o significado das culturas. Complementando essa ideia, vale citar Goto $^{3}$ (2008, p. 67), quando afirma ser uma ciência descritiva dos fenômenos que postula por fenômeno todo aparecer (erscheinen) de algo à consciência. Ele concorda que a fenomenologia se caracteriza também por ser uma ciência descritiva da consciência, ou melhor, uma analítica intencional. A analítica intencional significa, no sentido atribuído por Husserl, o estudo descritivo dos fenômenos a partir da análise da estrutura da consciência, ou seja, daquilo que se manifesta.

Ao considerar o caráter idealista da fenomenologia, McGrath (2005, p. 277) afirma que a corrente idealista não nega a existência das coisas materiais no mundo. No entanto, o idealismo defende que apenas é possível conhecer a imagem dos objetos como aparecem para o sujeito

${ }^{3}$ Psicólogo, doutor em Psicologia pela PUC Campinas, mestre em ciências da religião pela universidade metodista de São Paulo e membro do círculo Latino-americano de Fenomenologia (CLAFEN). 
conhecedor, ou o modo como é experimentado, e jamais os objetos em si, como realmente são. "A área do idealismo que enfatiza este aspecto de uma forma particularmente intensa é por vezes chamada de fenomenalismo, uma teoria de acordo com a qual é impossível conhecer diretamente as realidades exteriores"; sendo que, apenas, é possível conhecê-las por suas imagens ou representações. A versão mais conhecida dessa abordagem é associada ao grande filósofo idealista alemão Immanuel Kant, que defende a teoria de que se deve lidar com as imagens ou representações dos objetos, e não com os objetos em si. Assim, ele traça a diferença entre o mundo dos fenômenos e os objetos em si mesmos, alegando que os objetos jamais podem ser diretamente conhecidos (MCGRATH, 2005, p. 277).

Enfim, a fenomenologia pode ser compreendida a partir do princípio de que, o que deve ser analisado é o que vem à consciência ou, melhor dizendo, intencionalmente, através daquilo que se manifesta. É o estudo dos fenômenos que não podem ser negados porquanto são repletos de significado para as pessoas que os experimentam, como no caso da experiência da fé, da busca pela transcendência, por Deus, da crença na certeza de que Ele existe. E isso é inerente ao ser humano, independentemente de época ou cultura.

\subsection{O PRINCÍPIO DA REDUÇÃO FENOMENOLÓGICA}

Segundo o filósofo germânico Gadamer (1900-2002), discípulo de Heidegger, quando Husserl defende o conceito de "redução", ele tem em vista a rejeição de toda teoria conhecida à priori, quando algo se dá a conhecer, ou seja, quando é trazido à consciência. É diferente de se ocupar o que é inconsciente como postula Freud. Na essência, a redução fenomenológica pretende suspender todo posicionamento anteriormente conhecido para possibilitar o estudo dos fenômenos "puros". Para o autor, a redução tem como meta descortinar sem qualquer parcialidade inicial toda a riqueza dos fenômenos que se dão por si mesmos (GADAMER, 2012, p. 161).

Ales Bello (1998, p. 19) entende que a tarefa da fenomenologia se concretiza com a redução eidética, ou seja, redução à essência do significado do fenômeno. Em outras palavras, o método fenomenológico é caracterizado pelo fato de colocar "entre parênteses, por fazer a redução, em primeiro lugar de todos os pré-conceitos e dos conhecimentos já sedimentados e até mesmo da própria existência das coisas, para pôr em evidência, na sua essencialidade, a dimensão da consciência" (ALES BELLO, 1998, p. 45). Nesses termos, a autora destaca três vias da redução fenomenológica, propostas por Husserl. A primeira se chama de "cartesiana", um termo emprestado da matemática, com a qual se coloca entre parênteses o tema da existência que se deseja compreender. 
Sobre esta primeira via, Ricouer $(2009$, p. 150) concorda que a fenomenologia nasce dentro desta ideia de se colocar entres parênteses, definitiva ou provisoriamente, a questão do ser, para se abordar como um problema autônomo a maneira de aparecer das coisas. É como numa sentença matemática onde se coloca entre parênteses aquilo que se quer trabalhar primeiro, sem a interferência dos outros fatores. Este é o sentido da primeira via da redução que Husserl chama de cartesiana. Nesta via, o observador age como se não soubesse nada a respeito do objeto, evento ou fenômeno. E deixa que o objeto fale por si. É necessário deixar de lado por um tempo, fora dos parênteses, as ideias pré-concebidas, ou pré-conceitos, para que aflorem outras desconhecidas, nem imaginadas sobre o fenômeno que se quer estudar.

A segunda via da redução, de acordo com Ales Bello (1998, p. 45), é o caminho por onde o sujeito é tomado em conjunto, considerando sua relação com a coletividade. Já, a terceira via da redução parte da situação cultural contemporânea, superando os vários domínios do saber configurado, para captar a finalidade última do processo humano como processo histórico, ou seja, tem a ver com o contexto cultural do sujeito e toda a sua história.

Portanto, compreender as reduções propostas por Husserl é de suma importância para seu método fenomenológico que quer captar a essência dos fenômenos, livre de ideias pré-concebidas que escondem as características originais do objeto de estudo. Vale considerar ainda, que as vias de redução consistem em colocar entre parênteses o que se quer estudar, relacionar com o coletivo e com o fator cultural, tão importante para as missões transculturais.

\subsection{O MUNDO DA VIDA NA FENOMENOLOGIA}

Outra expressão destacada por Husserl, "mundo da vida", foi seguramente cunhada em oposição ao "mundo da ciência", que exigia sua supremacia, segundo Gadamer (2012, p. 167). Um olhar para o campo de visão da etnologia ou da história ensina que espaços e tempos geram mundos da vida extremamente diversos, "nos quais, coisas extremamente diversas são consideradas como obviedades inquestionáveis." O autor reconhece que Husserl "viu finalmente se abrir para si, no esclarecimento do mundo da vida, o caminho para uma última clareza e para uma nova sinceridade e racionalidade" (GADAMER, 2012, p. 207, 208).

Segundo Wagner (2012, p. 17), a psicologia fenomenológica de Husserl estende suas fronteiras para além da consciência individual. Enfatiza que "o intersubjetivo reduzido fenomenologicamente e apreendido concretamente é concebido como uma sociedade de pessoas que compartilham uma vida consciente."4.

Por fim, Gadamer (2012, p. 162) afirma que "não se alcança uma via de acesso ao conceito

"Passagens extraídas por Wagner do artigo de Husserl "Phenomenology" na Enciclopédia Britanica. Vol. 17. 14. ed. Chicago: Chicago Ed., 1947, p. 699-702. 
do mundo da vida [...], quando não se compreende este conceito a partir do conceito da ideia da redução transcendental." Da mesma forma, é preciso conhecer o fato de que a "nova fenomenologia" do mundo da vida pretende ser a própria fenomenologia transcendental finalmente desprovida de toda e qualquer antecipação "ingênua" e conduzida de maneira livre de preconceitos.

Em síntese, a expressão "mundo da vida", defendida por Husserl como um ambiente necessário para as investigações nas pesquisas de campo, surge em oposição ao "mundo da ciência" que desejou reivindicar para si a suma da verdade. No mundo da vida a ser considerado na fenomenologia, encontram-se os recursos para a condução de estudos com base naquilo que se é e se faz conscientemente, intencionalmente, no encontro com outros sujeitos e dentro de um contexto cultural.

\subsection{A DESCRIÇÃO FENOMENOLÓGICA}

Para a ciência, a fenomenologia se apresenta como possibilidade de um método qualitativo e, portanto, descritivo. Ales Bello (1998, p. 24) considera que a descrição fenomenológica se distingue em três pontos: O primeiro ponto é um procedimento filosófico que não pode configurarse num sentido indutivo, nem dedutivo, mas se funda na capacidade intuitiva do ser humano que teoriza tal capacidade pela reflexão. O segundo ponto é que não se trata de uma descrição de uma enumeração ou uma catalogação, mas visa captar o significado das coisas. E, o terceiro ponto não é uma interpretação, e sim, uma arqueologia que visa uma reconstrução. É um desconstruir para compreender o construído.

Ales Bello (1998, p. 36) afirma que a descrição fenomenológica foca na vida da consciência do sujeito, analisando as experiências vivenciais e, da mesma forma, investiga a intersubjetividade, analisando as concepções de mundo. Husserl deseja que se possa comparar os diversos mundos e que se possa levar a termo uma crítica mediante a qual se chegue definitivamente a uma verdade válida universalmente, de modo a conduzir à unidade aquilo que é múltiplo, à união de um mundo humano com muitos mundos familiares, em que se constitui o mundo verdadeiro (ALES BELLO, 1998, p. 81).

Para Ales Bello (1998, p. 81), o que importa é descobrir que apesar da diversidade, todos pertencem ao mesmo mundo e podem penetrar teórica e praticamente no mundo do outro graças à essa pertença comum. Obtém-se aí um duplo resultado: o de compreender aquilo que é estranho e o de esclarecer cada vez mais as estruturas do mundo da experiência. Segundo Husserl, isso é possível porque, como cientista, pelo fato de pertencer à cultura ocidental, ele conseguiu elaborar 
um método que permite captar as estruturas do mundo da vida. "Trata-se, portanto, de uma ciência descritiva do mundo circunstante, realizada com base naquilo que é pré-dado, obtida através de uma observação controlada teoricamente". É um método que capta as estruturas do mundo da experiência.

Segundo Ales Bello (1998, p. 84), Husserl não só identificou as experiências vivenciais, mas também ressaltou a sua estrutura em seus dois componentes reais das mesmas experiências: o noético (intencional) e o hilético (material). Assim, à luz dessas orientações é possível analisar justamente aqueles traços das culturas pré-científicas que atraíram a atenção dos estudiosos de outras culturas, Lèvy-Bruhl e Lèvy-Strauss, para indicar que eles podem ser lidos de maneira fenomenológica.

Na obra Ideias para uma fenomenologia pura, Husserl usa a expressão: dados materiais ou hiléticos. E, para o elemento específico da intencionalidade ele já introduzira em outro lugar o termo noesis, derivado da palavra grega nous, que tem também o sentido de significação. Ele termina dizendo que "a corrente do ser fenomenológico tem uma camada material e uma camada noética". A camada noética se refere ao significado do material (ALES BELLO, 1998, p.87, grifo da autora).

É importante considerar que a análise das culturas antigas é extremamente útil para compreender a própria cultura ocidental, "diferente" com relação às antigas, mas de alguma maneira ainda ligadas a ela através da presença de experiências vivenciais que perderam a sua significação originária. Na cultura ocidental aconteceu um processo de intelectualização "que tem privilegiado o momento noético". Por isso é difícil reconstruir a concepção primitiva do mundo, que em grande parte perdeu-se, mas que, graças ao método fenomenológico, pode-se "trazer novamente à luz" (ALES BELLO, 1998, p. 92).

Um bom exemplo de investigação seria o de compreender as raízes do pensamento sobre a inferioridade de pessoas solteiras com relação às casadas e sua aparente dívida para com a "normalidade" do grupo. Essa prática, estando presentes nas mais diversas culturas, é possível ser investigada através da arqueologia fenomenológica.

Conclui-se que a descrição fenomenológica, das estruturas do mundo da vida, leva em consideração o significado e a intenção nos dados materiais (hiléticos) e intencionais (noéticos) que estão na essência dos eventos, ou fenômenos. E isto se dá, colocando-se entre parênteses, temporariamente, o evento em si, para não ser ofuscado pelas ideias pré-concebidas ou os préconceitos. Também, desta forma, pode-se chegar a compreender o fundamento de algo já sedimentado ao longo do tempo, através de uma desconstrução, visando uma compreensão de algo 
que se quer analisar em sua estrutura e aparência.

\subsection{A EMPATIA NAS PREMISSAS FENOMENOLÓGICAS}

Entre os problemas mais comuns no trabalho missionário transcultural estão os malentendidos, quando o ideal é que haja influência mútua e um convívio respeitoso no encontro e relacionamento de pessoas diferentes, afirma Oliveira (2008, p. 61). Para ele, isso, às vezes se relaciona a aspectos culturais e sociais, outras a aspectos linguísticos, e, superá-los é um desafio que permanece diante de cada missionário. Estas são questões que exigem, além de conhecimento refinado do comportamento de uma determinada cultura, uma sensibilidade no contato e diálogo. E a fenomenologia se coloca à disposição para fornecer premissas para a análise e a compreensão dessas diferenças e desencontros. E uma premissa valiosa ao método fenomenológico é a empatia.

Segundo Gadamer (2012, p. 205), para Husserl, o problema da intersubjetividade só pode ser resolvido a partir do "eu" transcendental e de suas realizações constitutivas. O outro só pode ser compreendido como um "ser como eu" por meio da realização de uma empatia “transcendental”. Edith Stein (1992, p. 57) enfatiza que a empatia não é uma simples percepção externa, mas uma percepção interna, no interior. É apreender, perceber de dentro a consciência. É um ato perceptivo e aperceptivo, uma experiência centrada na vivência do outro. "Eu sinto dentro, no interior [...]. Sou eu que sinto o outro, mas o conteúdo que sinto do outro não é originário, pois não vem de mim, vem do outro", explica Manganaro 5 .

Segundo Manganaro, empatia e mística são duas vivências centradas na alteridade. Já, a simpatia e antipatia, no pensamento de Edith Stein (1992, p. 68-70), são movimentos espontâneos superficiais com relação às pessoas, ambientes e situações. A psique em Husserl (simpatia/ antipatia) é automática e inconsciente. Já o que é consciente, é intencional (empatia). Neste sentido a psicologia é ciência humana cujo objeto de estudo é a psique (involuntária/ mecânica), e a fenomenologia é também ciência humana filosófica, mas que analisa a consciência, que é intencional. Nesse sentido, a psique pode ser respondida pela filosofia e não pela psicologia.

A psicologia em Freud é sobre o inconsciente, o automático e o involuntário. Já, a fenomenologia em Husserl pesquisa a consciência intencional. É a pesquisa da essência. E a diferença entre as duas é o método de estudo (ontologia). E, para Manganaro (2014), é interessante notar que tanto Freud quanto Husserl foram alunos de Brentano (1838-1917), ex-sacerdote católico e filósofo alemão, considerado o fundador da que hoje é chamada psicologia existencial.

Neste pensamento, Manganaro questiona: Quem é o educador do ponto de vista fenomenológico? É aquele que ajuda o ser humano a se libertar. Aquele que é empático não induz,

${ }^{5}$ MANGANARO, Patrizia. Empatia, Curitiba, 2014. Palestra realizada na PUCPR, Campus Curitiba em 6 e 11 agosto 2014. Patrizia Manganaro é filósofa e pesquisadora da Fenomenologia como expõe Ales Bello e Edith Stein a partir dos escritos de Husserl. 
mas conduz. É o que procura compreender talentos e qualidades dos outros. Ajuda a formar a individualidade e conduzir à liberdade. Edith Stein (2002, p. 121), em sua leitura analítica, conclui que através da fenomenologia, pela empatia o outro se faz presente em mim. Da mesma forma, na experiência mística, Deus se faz presente em mim. Neste sentido, a fenomenologia provoca conversões, segundo Manganaro, por causa da intencionalidade da consciência que é cheia de conteúdo. Husserl privilegia o sentir e não somente o ver como a filosofia. São as experiências vivenciadas, sentidas como um corpo vivo sente, acontecendo a partir da consciência de si próprio.

Do ponto de vista da fenomenologia das religiões, o cristianismo é classificado como a religião do amor. E é um grande problema filosófico. Através da empatia com o outro e com o Outro, em relação a mística, entra o amor. Fenomenologia é filosofia da consciência que é centrada no outro, e isto se chama amor, e é serviço para a humanidade, complementa Manganaro.

Enfim, a empatia apresenta-se como um importante componente metodológico para a abertura e compreensão do outro e de si mesmo através da relação com o outro, e de maneira intencional, consciente. E, dessas compreensões é possível estabelecer relações entre a alteridade e religião, como no exemplo do cristianismo sob a premissa do amor de doação como se apresenta na Bíblia.

\section{A ARQUEOLOGIA FENOMENOLÓGICA E A ANTROPOLOGIA CULTURAL}

A arqueologia fenomenológica das culturas é um tema recorrente quando se trata de missões transculturais, por ser um instrumento de pesquisa válido cientificamente.

A Antropologia Cultural, uma nova ciência humana, surge de uma revisão crítica, quando, no final do atormentado século XX, o contato com povos diferentes despertou no ocidente o interesse por "outras" formas de vida que se procurou conhecer e estudar em sua realidade peculiar. E alguns pensadores como Lucien Lévy-Bruhl, Claude Lévi-Strauss e Margaret Mead iniciaram pesquisas teóricas e investigações de campo em populações distantes no espaço e ao mesmo tempo, remotas no tempo (ALES BELLO, 1998, p. 10).

$\mathrm{Na}$ definição de Husserl $^{6}$, a arqueologia fenomenológica se refere a uma operação de escavação nos elementos constitutivos do mundo da experiência. É uma indagação regressiva voltada a determinar o sentido das coisas. Aquela que ele chama de regressão. Este trabalho de busca estabelece uma analogia com "a escavação do arqueólogo, que tenta descobrir e reconstruir o caminho através do qual o material ficou sedimentado" (ALES BELLO, 1998, p. 18). A “experiência vivencial” ou “o que se vive”, segundo Ales Bello (1998, p. 24) foi traduzido do termo erlebnis, dos escritos de Husserl. Ele se refere aos atos característicos da interioridade do

${ }^{6}$ Transcrito de um manuscrito de Husserl com a sigla C $16 \mathrm{IV}$, intitulado Arqueologia fenomenológica. E. Husserl, Ms. Trans. C 16 IV, Phanomenologische Archäologie, 1932. 
ser humano que vão desde a percepção até a recordação, a imaginação, o pensamento e assim por diante, que são elementos estruturais e constitutivos da consciência, e tem a ver com cosmovisão.

Entre os manuscritos da filósofa Edith Stein, foi encontrado um texto em que se estabelece uma conexão entre fenomenologia e cosmovisão, "certamente não no sentido da redução da fenomenologia a uma concepção do mundo entre as outras, mas sim da contribuição que esse tipo de investigação pode dar na formação de um critério interpretativo da realidade."7 (ALES BELLO, 1998, p. 24).

A pesquisa de August e Fernandes (2015, p. 4) sobre pessoas solteiras que vivem como missionárias em outras culturas, aponta que as concepções de mundo e o modo como se vive (a subjetividade) vão adquirindo forma desde a infância, de acordo com o que se experimenta e se vivencia no contexto cultural. Constituem-se, desta forma, os processos de subjetivação. "Na cultura ocidental há modos de viver que diferenciam as pessoas solteiras das casadas. Isto ficou visível em pesquisa com pessoas solteiras protestantes". E, em outras culturas, certamente se observam outras formas de diferenciação que podem afetar a ação e a mensagem da pessoa solteira no campo missionário, pelo fato de ser solteira. É um exemplo de cosmovisão que se pode identificar numa pesquisa de campo.

Para Kirk (2006, p. 121), embora usando termos diferentes e uma variedade de categorias, "muitos estudiosos da cultura encontram três componentes fundamentais: crenças, valores e formas exteriores". A interação entre cada nível é tão intensa que se deve ter cuidado para não tratar como realidades inteiramente distintas. Para a aproximação, compreensão e análise de outra cultura, é fundamental levar isso em conta.

Neste sentido, é importante considerar que o termo cultura na antropologia/ etnologia, segundo Reimer (201, p. 210) é entendido não como uma parte da vida humana, mas a totalidade do comportamento, e é a base para esse comportamento, de uma determinada sociedade ou grupo. "É o modo de vida de um povo". O autor entende que se aprende sobre o contexto de vida das pessoas quando se estuda sua cultura. Isso significa que se analisam as coisas que essas pessoas têm, fazem, pensam e creem. E, para a teologia cristã, a Bíblia é o parâmetro de análise de todos os valores, estruturas e comportamentos de uma cultura (REIMER, 2011, p. 214).

Desta forma, a arqueologia fenomenológica das culturas se mostra de grande utilidade por investigar de maneira profunda a essência dos traços culturais de um povo desde suas origens. $\mathrm{E}$ neste sentido, entra para ajudar na compreensão desta busca, a antropologia cultural. Para o estudioso Lèvy-Strauss, a antropologia cultural procede de uma determinada concepção do mundo e de uma maneira original de colocar os problemas. As duas formas são descobertas com 
o estudo de fenômenos sociais que ocorrem na sociedade do observador, os quais, porém, “devido às grandes diferenças que apresentam em comparação com os fenômenos mais simples, revelam algumas propriedades gerais da vida social, que o antropólogo considera como objeto específico"8 (ALES BELLO, 1998, p. 69).

A diversidade cultural despertava a atenção de Lèvy-Bruhl ${ }^{9}$, ao ponto de induzi-lo a falar de uma lógica "fundada essencialmente numa lei diferente: a lei da participação, de onde ele como filósofo deduzia, no fundo, considerações gerais sobre a relação entre as culturas, relacionando-as com os princípios cognitivos e com os processos funcionais do pensamento." Para ele é essencial encontrar a razão de tal comparação (ALES BELLO, 1998, p. 69).

Segundo Ales Bello (1998, p. 70), esses dois estudiosos apresentam uma exigência provocada pela curiosidade do intelectual ocidental, que pretende realizar uma investigação não somente em torno da sua cultura, mas também sobre as outras culturas, utilizando as categorias produzidas por uma longa tradição de pensamento. "É a comparação, portanto, que se torna o tema central da investigação e é aqui que os caminhos dos dois investigadores se dividem". O primeiro põe em destaque o contraste, o segundo tende a destacar uma busca pela maior afinidade. Ao comparar as posições dos dois antropólogos, Ales Bello (1998, p. 74) detecta um ponto de contato na atitude de respeito de ambos, dedicado à autonomia cognitiva e prática do mundo mais antigo, como as culturas africanas.

Segundo Ronaldo Lidório ${ }^{10}(2003)^{11}$ a antropologia cultural, funcionalmente definindo, "é um instrumento de reconhecimento das perguntas existentes em certa cultura, socialmente interpretadas ou não pelo próprio grupo, entretanto necessárias para se diagnosticar os pontos de tensão sócio etnológico ali existente". Desta forma, provê as ferramentas necessárias para o mapeamento cultural do grupo alvo através da definição "da hierarquia social, hierarquia sócioespiritual, expressões ritualísticas e cerimoniais, cosmologia, cosmovisões e costumes, linguagem interativa e comunicabilidade". Para ele, o alvo da antropologia cultural, "missiologicamente" falando, é levantar as perguntas socialmente relevantes a fim de receber respostas biblicamente centradas, sendo que, o alvo final é fomentar transformação de vida e sociedade através de um evangelho que faça sentido na cultura receptora e não apenas na mente e coração daquele que transmite.

Em termos práticos, Lidório (2003) considera que o trabalho da antropologia cultural é saber quais são as perguntas antes de tentar respondê-las pela Teologia bíblica, pressupondo que já se sabe tudo de antemão. Isso na fenomenologia é possível através do "colocar entre

${ }^{8}$ LÈVY-STRAUSS, Claude. Antropolgia strutturale, tr. It. De Paulo Caruso, Il Saggiatore, Milão 1990, p. 380.

${ }^{9}$ LÈVY-BRUHL, Lucien. Bulletin de La Société de Philosophie, 15 de fevereiro de 1923, p. 20-21.

${ }^{10}$ Ronaldo Lidório é pastor, teólogo, missionário e escritor. Atuou quase dez anos na África com plantio de igrejas e tradução bíblica para a língua Limonkpeln de Gana. Atualmente, lidera uma equipe missionária na Amazônia.

"LIDÓRIO, Ronaldo. O desafio do preparo missionário em um contexto de prejuízo histórico. 2003. In Ronaldo \& Rossana Lidório. Disponível em: <http://www.ronaldo.lidorio.com.br/index2.php?option=com content\&do_pdf=1\&id=19>. Acesso em: 14/11/2015. 
parênteses", para primeiro compreender na essência o fenômeno, sem as ideias pré-concebidas sobre este fenômeno. É a redução da qual se refere Husserl.

Segundo Lidório, é necessário deixar o simplismo óbvio de lado, e descobrir quais seriam as áreas de estudo na antropologia cultural que fariam os missionários mais bem preparados para o grande desafio. E considera que dentre as mais variadas áreas da antropologia como “Antropologia Cultural, Etnicismo, Etnologia, Costumes e Culturas, Fenomenologia Religiosa e Comunicação Social, há duas altamente relevantes para os candidatos à obra missionária transcultural, que são Fenomenologia da Religião e Etnologia". A relevância destas duas áreas de estudo deve-se mais à observação dos comuns erros de campo do que em uma tentativa de estruturar um currículo ideal de conhecimento antropológico. Para isso é necessário reconhecer que nem tudo o que é diferente é religioso, nem tudo o que é cerimonial é demoníaco e nem tudo o que é cultural é puro.

Portanto, a antropologia cultural tem como missão mapear, localizar e fazer as perguntas certas, pois, para a missão bíblica, é necessário apresentar as respostas certas, as respostas biblicamente corretas.

\section{O PAPEL DA RELIGIÃO PARA A CULTURA}

Diferentes costumes e mentalidades diversificam os povos, mas se trata sempre de seres humanos, portanto de “outros”. Na análise de Ales Bello (1998, p. 106), por exemplo, é justamente o contato com povos que pertencem a culturas não ocidentais, que permite perceber a importância do papel da religião naquele ambiente cultural.

Em relação à Fenomenologia da Religião, Ales Bello (1998, p. 107) confirma que se sabe pouco sobre o interesse de Husserl, mas, pelos indícios que deixou, pode-se afirmar que ele identifica claramente "um caminho fenomenológico rumo à dimensão religiosa examinada na sua vertente subjetiva enquanto homo religiosus". Quem publicou pesquisas sobre as possibilidades da fenomenologia para o campo religioso, foram Van der Leeuw e W. Dilthey, que tomaram as análises histórico-culturais como objeto principal de suas investigações. $\mathrm{O}$ fenomenólogo holandês Gerardus Van der Leeuw, em sua obra Fenomenologia da religião, de acordo com Ales Bello (1998, p. 11), demarcando os limites entre a história e a filosofia, investigou "o sentido da experiência religiosa, mostrando sua especificidade e de maneira indireta, a impossibilidade de ser suprimida".

A pesquisa de Van der Leeuw parte de um plano existencial para demonstrar que tudo o que é produzido pelas capacidades humanas é a resposta à busca de um sentido. "O homo 
religiosus” gostaria de entender a vida para dominá-la e por isso procura sempre novos poderes superiores, porém "toma consciência de que jamais poderá superar a fronteira e que jamais poderá alcançar o poder supremo, mas é este que o alcança, de uma forma incompreensível e misteriosa" (Ales Bello, 1998, p. 109). A experiência de Van der Leeuw, sem dúvida, representa um marco limiar no domínio das pesquisas em torno da dimensão religiosa, identificando sua especificidade.

Quanto à religiosidade na cultura, Ales Bello (1998, p. 117) explica que não se trata de demonstrar a existência de Deus, que cabe à metafísica, mas sim descobrir o modo natural e espontâneo, por parte do fiel, de relacionar-se com Deus e fazê-lo através de uma crítica filosófica. Esta crítica destaca que não é o pensamento filosófico, mas é o pensamento espontâneo que afirma a Deus. Desta forma, “a existência de Deus não é objeto de uma demonstração, mas sim de uma redução, a fenomenológica, justamente, que põe em destaque o movimento espiritual mediante o qual se capta a sua presença” (ALES BELLO, 1998, p. 117).

Nas culturas mais antigas, "toda ação da vida cotidiana está ligada à sacralidade". Para descobrir os momentos que dão suporte a esse tipo de mentalidade, e justificá-la, num ponto de vista fenomenológico, é necessário remontar às experiências vivenciais que estão na base daquela "cosmovisão", ou em termos fenomenológicos, "é preciso descobrir aquelas configurações particulares do mundo-da-vida e estudar a sua estrutura [...] a respeito dos componentes essenciais da mesma experiência" (ALES BELLO, 1998, p. 123). Nas culturas da África, por exemplo, há uma forte valorização da tradição. E a análise fenomenológica permite compreender o papel fundamental da experiência religiosa na mentalidade africana, em que toda convocação aos valores e às práticas tradicionais é uma convocação religiosa que dá sentido à realidade.

Por outro lado, Ronaldo Lidório (2003), denomina de "neurose espírito-fenomenológica" a tendência que os missionários têm de analisar religiosamente todo e qualquer fenômeno, "interpretando-o como quem chegou para dissecar a religiosidade cultural sem, entretanto, ver o povo como uma sociedade que vive e não apenas cultua”. E este é o perigo quando se adentra em outra cultura.

Para Kirk (2006, p. 113), “estamos tão imersos em nossa própria cultura que fica difícil ver os seus defeitos - ou perceber força e beleza em outras culturas". O que é familiar para si geralmente é tomado como padrão para julgar o que os outros fazem. Ele entende que, quando exercida corretamente, "a distinção ética e cultural reflete a rica diversidade da vida humana e permite que as pessoas tenham um senso de segurança ao serem capazes de se identificar com um agrupo que tenha sua própria história, costumes e tradições". Em relação à evangelização e missões, Kirk (2006, p. 111) afirma que a vinda de Deus como um ser humano "num momento 
articular da história e numa localidade geográfica específica (encarnação) é uma das chaves para entender o relacionamento entre evangelho e cultura".

Em síntese, é o contato com povos que pertencem a culturas não ocidentais, que revela com maior clareza o papel desempenhado pela religião, bem como a sua penetração, a sua difusão e a sua importância nos mais diversos ambientes culturais.

\section{A TEOLOGIA E A ABORDAGEM FENOMENOLÓGICA}

A teologia, apesar de ter aspectos comuns com as ciências da religião, não pode ser uma ciência propriamente dita, segundo Goto (2004, p. 68), pois ela tem algumas características filosóficas, mas não é filosofia da religião. E a explicação que ele dá, é de que a teologia não possui em sua metodologia a certa "neutralidade" e imparcialidade que impõe um método. "A teologia sempre investiga o objeto relacionado com sua proposta religiosa ou confessional, baseando-se na fé e revelação, impossibilitando a imparcialidade ou o afastamento da subjetividade."

Neste sentido, Tillich (2011, p. 119), quando escreve sobre as considerações metodológicas para tratar da realidade da revelação, por exemplo, acredita que a importância da abordagem metodológica da fenomenologia com base nos escritos de Husserl ${ }^{12}$, está em sua exigência de que o sentido de uma noção seja esclarecido e circunscrito antes que se determine sua validez, antes que se aceite ou se rechace tal noção. Para Tillich, a teologia deveria aplicar a abordagem fenomenológica a todos os seus conceitos básicos. Dessa forma, forçaria seus críticos a ver o que significam os conceitos criticados e "obrigando a si próprio a fazer descrições cuidadosas de seus conceitos e a usá-los com consistência lógica, evitando assim o perigo de tentar preencher as lacunas lógicas com material devocional."

Além do mais, Tillich (2011, p. 119) reconhece que uma descrição fenomenológica poderia ser testada na sua capacidade de descrever um quadro que seja convincente, "de torna-lo visível a qualquer pessoa que esteja disposta a olhar na mesma direção, de iluminar com ele outras ideias afins e de tornar compreensível a realidade que estas ideias pretendem refletir". Segundo ele, “a fenomenologia é a forma de considerar os fenômenos tal como 'se apresentam', sem a interferência de preconceitos e explicações negativas ou positivas."

No entanto, o método fenomenológico deixa sem resposta uma questão que é decisiva para sua validez, no entender de Tillich. Onde e para quem se revela uma ideia? Segundo ele, o fenomenólogo responde: “tome como exemplo um evento revelatório típico e veja nele e através

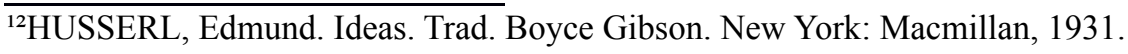


dele o sentido universal da revelação. Esta resposta se mostra insuficiente tão logo a intuição fenomenológica se depare com exemplos diferentes e talvez contraditórios de revelação" (TILLICH, 2011, p. 119).

De acordo com Tillich, a fenomenologia não pode responder à pergunta, nesse caso, pelo critério de escolha de um exemplo, e sim se for introduzido um elemento crítico na fenomenologia 'pura'. A fenomenologia dependeria de uma revelação que foi recebida e considerada como final e que é crítica com respeito a outras revelações. Contudo, a abordagem fenomenológica seria preservada. "Trata-se de uma fenomenologia crítica que une um elemento intuitivo-descritivo com um elemento existencial-crítico", que é o critério "segundo o qual se seleciona o exemplo; o elemento intuitivo-descritivo é a técnica mediante a qual se descreve o sentido que é manifesto no exemplo" (TILLICH, 2011, p. 120).

Em outras palavras, “o caráter concreto e único do exemplo (p. ex., a visão reveladora de Isaías) está em tensão com a reivindicação universal da descrição fenomenológica segundo a qual o significado deste exemplo é válido para todos os exemplos”. Para Tillich, esta tensão é inevitável. No entanto, pode-se reduzi-la de duas formas: "Por uma comparação de diferentes exemplos ou pela escolha de um exemplo em que absoluta concretude e absoluta universalidade estejam unidas”. Mas Tillich deduz que a primeira forma leva à abstração, que reduz seu significado a uma "generalidade vazia (p. ex., uma revelação que não é nem judaica, nem cristã, nem profética, nem mística)”. Segundo Tillich, é precisamente isso que a fenomenologia deseja superar. "A segunda forma está baseada na convicção de que uma revelação especial (p. ex., a aceitação de Jesus como o Cristo por Pedro) é a revelação final e, em consequência, é universalmente válida" (TILLICH, 2011, p. 120).

Portanto, para Tillich, a fenomenologia crítica é o método mais adequado para fornecer uma descrição normativa dos significados espirituais, e a teologia deve usá-la ao tratar de cada um de seus conceitos básicos. Cerbone (2012, p. 198) reconhece um sentido compartilhado de que a fenomenologia não somente é possível, como filosoficamente indispensável. Além disso, “a despeito de muitas diferenças, tanto no nível programático como no nível do detalhe, [...] Husserl, Heidegger, Sartre e Merleau-Ponty - concordam que a fenomenologia não só merece ser feita como aspira a ser o método para a filosofia."

Ales Bello (1998, p. 97) aplica as três vias da redução dentre as muitas propostas por Husserl e detectáveis nas suas análises, que levam à questão de Deus como termo último, como justificação da intersubjetividade e da vida ética do ser humano. "Os breves acenos à problemática que concerne à questão do fundamento último", que Husserl define como Deus, permitem tirar 
algumas conclusões, no entender de Ales Bello (1998, p. 101).

Em primeiro lugar, "não se parte da dúvida (sobre a existência de Deus) para se chegar a uma confirmação, mas, ao contrário, Deus é o termo necessário de um processo de pensamento que se eleva da experiência de ordem física e factual." Em segundo lugar, "trata-se do Deus dos filósofos." Husserl define Deus como "absoluto" e "fundamento". Para ele, sobrevoar e não aprofundar o sentido da consciência religiosa, não implica certamente a sua negação, "mas indica somente que são mantidas distintas as duas esferas, tanto a filosófica como a religiosa, que levam ao mesmo princípio, mas através de modalidades diferentes" (ALES BELLO, 1998, p. 101).

Portanto, é difícil negar a importância da fenomenologia como método de análise em pesquisas na área da teologia. Sobre isso concordam Tillich, Husserl, Heidegger, Sartre, MerleauPonty e Ales Bello. Em grande parte, isso se deve ao caráter diferenciado da teologia estreitamente ligada às suas confessionalidades. E a fenomenologia crítica é o método mais adequado para fornecer uma descrição normativa dos significados espirituais.

\section{AS AÇÕES MISSIONÁRIAS, A FENOMENOLOGIA E A ÉTICA DO RESPEITO}

Para Reimer (p. 208), no trabalho missionário do século XIX e parte do século XX, os missionários ocidentais (europeus e norte-americanos) estavam tão convictos de sua superioridade cultural e da inferioridade da cultura abordada que nem se davam ao trabalho de estudar o contexto no qual trabalhavam. No entanto, após a Segunda Guerra Mundial (19391945), “os teólogos das jovens igrejas da Ásia, da África e da América do Sul não estavam mais dispostos a aceitar o modelo da teologia ocidental", segundo Reimer (2011, p. 209). "Levantou-se um protesto contra o imperialismo missionário do ocidente. [...] Hoje também os evangelistas aceitam a necessidade de diálogo com teólogos de diferentes culturas”, enfatiza o autor.

De acordo com Barros (2003, p. 122), a missão transcultural continua ainda cometendo erros na atualidade, porque, junto com a mensagem, leva também seus valores culturais de origem. Certamente é preciso criar uma mentalidade interdisciplinar e ampliar a compreensão do mundo para uma aproximação entre culturas. Desta forma, as premissas da fenomenologia, no que concerne à empatia e à atenção àquilo que se manifesta, concedem respostas para reagir a essa possibilidade sugerida por Barros.

Além do mais, segundo Reimer (2011, p. 205), não se pode condenar os homens e sua história por princípio, pois a história da humanidade é também a história de Deus. $\mathrm{O}$ autor argumenta que a igreja não é implantada contra uma cultura, mas dentro dela. "Judeu para judeus e grego para gregos" a exemplo de Paulo em sua atividade missionária (1Co 9.19ss), e segue 
procurando por indícios sobre Deus "no meio das divindades gregas e os encontra na adoração ao verdadeiro Deus" conforme Atos 15. E implanta igrejas de utilidade pública com diálogo e cooperação.

A partir da situação cultural do ocidente com suas tradições, é preciso tomar as iniciativas para compreender "os outros". Mas, de acordo com Ales Bello (1998, p. 67), a tentativa de sair de seus próprios limites tem como contrapartida a necessidade de submeter-se a si próprio à crítica, e investigar as próprias estruturas. Para Rogers (1981, p. 283), psicólogo, criador da linha teórica conhecida como Abordagem Centrada na Pessoa, compreender a fundo as ideias e os sentimentos de outra pessoa, com o significado que esta experiência tem para ela, e, "inversamente, ser profundamente compreendido por essa outra pessoa - é uma das experiências mais humanas e mais compensadoras e, ao mesmo tempo, uma das experiências mais raras." Ele também acredita na hipótese de que, "a maior barreira à comunicação interpessoal é a nossa tendência muito natural para julgar, para avaliar, para aprovar ou para desaprovar as afirmações de outra pessoa ou de outro grupo" (Ibid, p. 290).

Para o diálogo intercultural, compreender o sentido do mundo das vivências é fundamental. E isso se torna possível através das posturas do método fenomenológico. Amorese (2008, p. 96, 102) entende que a comunicação verdadeira não se dá de cima para baixo, mas compartilha e se faz na base da "horizontalização". Desta forma, se num projeto missionário, "seja nos confins da terra, seja em Jerusalém, não houver comunicação genuína, compromete-se o modelo divino, realizado em Jesus".

Porém Schutz (2012, p. 68) indaga sobre como é possível que a compreensão mútua e a comunicação realmente possam acontecer:
Como é possível que o homem realize ações significativas, com finalidades ou simplesmente habituais, que seja guiado por fins a serem realizados e motivado por determinadas experiências?
Os conceitos de significado, de motivos, de fins, de atos, referem-se a uma determinada estrutura da consciência, a determinado arranjo de todas as experiências segundo um tempo interior, a um certo tipo de sedimentação?
E a interpretação do significado atribuído pelos outros e do significado de suas ações por acaso não pressupõ̃e uma auto interpretação do observador ou de seu parceiro? Como é possível que eu, enquanto homem em meio a outros, ou como cientista social, encontre uma forma de abordar tudo isso a não ser recorrendo a um estoque de experiências pré interpretadas, construídas mediante um processo de sedimentação dentro de minha própria vida consciente?
E como é possível justificar métodos de interpretação das inter-relações sociais se eles não forem baseados em uma cuidadosa descrição dos pressupostos subjacentes e de suas implicações? (SCHUTZ, 2012, p. 68).

Para o autor, mesmo sendo cientista social, essas questões não poderiam ser respondidas pelos métodos das ciências sociais, pois demandam uma análise filosófica. E, a fenomenologia, 
bem como a psicologia fenomenológica, abriram caminho para essa análise e deram início a ela (SCHUTZ, 2012, p. 68).

Na perspectiva Bíblica, a realidade última da história é uma nova comunidade de pessoas de todas as raças e culturas juntas, adorando um Deus e único salvador através de um Espírito (Ef 2.18,20; Ap 7.9). Em primeiro lugar, a igreja não pode correr o risco de se identificar exclusivamente com qualquer cultura ou nação e, em segundo lugar, um grupo de cristãos não pode criar barreiras contra outros pelo uso excludente de símbolos culturais (KIRK, 2006, p. 115). $\mathrm{O}$ autor percebe na diferença cultural uma dimensão tanto conceitual quanto prática. Conceitualmente, não é fácil separar a crença no Evangelho dos valores e instituições da sociedade ocidental, como também é difícil relacionar o Evangelho às sociedades moldadas por sistemas de crenças bastante diferentes. Além do mais, a nova religião estrangeira, é vista como inferior, porque tem gerado uma sociedade (no Ocidente) com fama de promover uma indiferença aos valores espirituais, entre outros aspectos. "É uma religião considerada como não tendo uma mensagem clara diante dos dilemas morais da atualidade" (KIRK, 2006, p. 115,116).

Um exemplo dessa percepção é abordado por Oliveira (2008, p. 111), quando alega sua preocupação em como outros povos veem os brasileiros. $\mathrm{O}$ autor conta que realizou uma pesquisa com pessoas de dez nações de diferentes partes do mundo e descobriu que além de algumas características boas já conhecidas dos brasileiros como gentileza, hospitalidade e comida boa, surgiram alguns pontos que devem ser preocupação de quem quer se envolver e ser bem visto em outras culturas.
a) Superficialidade nos relacionamentos;
b) Conformismo com os erros;
c) Falta de pontualidade;
d) Insubmissão às regras (jeitinho brasileiro);
e) Desejo de sempre levar vantagem;
f) Forte sentimento de competição;
g) Certa malícia disfarçada em conversas de duplo sentido (OLIVEIRA, 2008, p. 111).

Os pontos de tensão citados descrevem bem alguns aspectos da cultura brasileira que interferem diretamente nas dificuldades que os brasileiros enfrentam no campo missionário ao se relacionarem com outras culturas e mostram que a cultura ocidental se percebe de forma equivocada, muitas vezes. Em termos fenomenológicos, como poderia ser tratada essa diferença de percepção e autopercepção no encontro entre culturas?

Ricouer (2009, p. 308), em sua crítica à fenomenologia reconhece que não se pode praticar um método sem prestar atenção aos seus limites. "É provável que descobrindo aquilo que o limita, também se descubra no que o justifica e o funda". É percebida aqui, uma limitação no método na 
descrição das aparências, e aí requer, para continuar a ser praticado, do auxílio de um tipo de pensamento outro em vez da descrição compreensiva daquilo que "aparece", diverso da exegese das "aparências". É uma crítica do autor à uma premissa da fenomenologia.

Nesse sentido, Ricouer (2009, p. 309), na tentativa de resolver esta questão, conclui que a posição absoluta do outro no respeito é o fundamento sempre anterior a um discernimento do aparecer do outro. É o que ele considera a ética do respeito. "Remontando, portanto, da ética do respeito à fenomenologia da simpatia, [...] a primeira possibilita a segunda". E protege o objeto a ser descrito, de equívocos de uma simples fenomenologia da simpatia. O autor percebe que Husserl mais tarde, em sua obra V Meditação, pretende respeitar o sentido que se liga à presença do outro, "como um outro que não é eu, como outro eu, que tem seu mundo, que me percebe, que se dirige a mim e estabelece comigo relações de intersubjetividade de onde saem um só mundo da ciência e seus múltiplos mundos e cultura”. Ele concorda que Husserl manteve até o fim a sua preocupação descritiva de respeitar a alteridade do outro (RICOUER, 2009, p. 311).

Para Ricouer (2009, p. 325), é possível, de fato, “descobrir analiticamente em cada afeto um momento de tomada de posição relativamente ao outro, por conseguinte, um ato de apreciação, de avaliação da existência-valor do outro". É por esse lado, segundo o autor, que todo afeto intersubjetivo pode ser situado com relação ao que ele chamou de ética do respeito. Sem dúvida, o método de Husserl foi sendo desenvolvido em meio a idas e vindas, e em meio a críticas como as de Ricouer explicitadas aqui. Mesmo assim, na atualidade tem sido muito utilizado em pesquisas de campo. Especialmente nos casos de encontro entre culturas.

O método fenomenológico foi reconhecido por Tillich (1999, p. 63) como absolutamente necessário para os estudos humanísticos. Ele achou curioso observar que, enquanto o existencialismo passou a ser geralmente aceito, o mesmo não se deu em relação a Husserl. "Contudo, hoje em dia, alguns filósofos e psicanalistas que aceitaram inicialmente o existencialismo para fundamentar seu trabalho, estão voltando para a fenomenologia (razão intuitiva)". Isto, porque, segundo Tillich, descobriram que sem este método, "o existencialismo não teria sido capaz de pronunciar palavra alguma."

Desta forma, a fenomenologia, como descrita aqui, principalmente da compreensão de Ângela Ales Bello, tem demonstrado seu valor e aplicabilidade também para o campo da teologia e especialmente para as missões transculturais. 


\section{CONCLUSÃO}

A fenomenologia sistematiza por Husserl, mesmo tendo sofrido críticas ao longo desses 100 anos de existência, e tendo sido por muitos, e por muito tempo esquecida, tem encontrado na atualidade um amplo espaço de aceitação como método descritivo, ou como preferem alguns autores, posturas de investigação e análise nas pesquisas de campo em várias áreas do conhecimento, incluindo a teologia. E, dentro do campo da teologia, encontra seu valor quando se requer um método considerado científico, que auxilie e dê credibilidade às pesquisas necessárias para as missões transculturais, especialmente no encontro entre culturas em seus valores religiosos.

A presente pesquisa reconhece suas limitações ao tratar de um tema amplo como a Fenomenologia, dada às vastas áreas e formas de sua aplicabilidade e também de algumas áreas de fraqueza na aplicabilidade do método, como acontece em outros métodos que necessitam sempre estar sendo atualizados através de novas pesquisas para manter seu valor científico. No entanto, é necessário investigar através de comparação e confronto, os modos de vida, de ser, de agir nas diversas culturas para se tentar compreendê-la. E o método fenomenológico, da forma como Ales Bello interpreta dos escritos de Husserl, apresenta-se como adequado a esta modalidade de investigação.

A fenomenologia tem condições de dar conta perfeitamente de ajudar a compreender a diferença entre culturas, principalmente no aspecto social e religioso, de onde surgem as questões a serem respondidas no âmbito da fé.

\section{REFERÊNCIAS}

ALES BELLO, Angela. Culturas e Religiões: uma leitura fenomenológica. Bauru: EDUSC, 1998.

AMORESE, Rubens. Fábrica de missionários - Nem leigos, nem santos. Viçosa: Ultimato, 2008.

AUGUST, Mariluce E. M.; FERNANDES, Marcio L. A conjugalidade na vida de fé em pessoas solteiras evangélicas brasileiras em missões transculturais: uma análise fenomenológica. In Anais do Congresso ANPTECRE, v. 05, 2015, 9p.

BARROS, Wilson Tadeu. Teologia da Missão. Londrina: Descoberta, 2003.

BÍBLIA online multilíngue. Nova Versão Internacional. Disponível em: $<$ HTTP://www.bibliaonline.com.br/index.jspa>. Acesso em: 3/12/2015.

CERBONE, David R. Fenomenologia - pensamento moderno. 2. ed. Petrópolis: Vozes, 2012. 
GADAMER, Hans-Georg. Hegel, Husserl, Heidegger. Tradução: Marco Antônio Casanova. Petrópolis: Vozes, 2012.

GOTO, Tommy Akira. Introdução à psicologia fenomenológica - a nova psicologia de Edmund Husserl. São Paulo: Paulus, 2008, p. 67. 2004, p. 67. O fenômeno religioso - a fenomenologia em Paul Tilich. São Paulo: Paulus, HUSSERL, Edmund. Ideas. Trad. Boyce Gibson. New York: Macmillan, 1931.

KIRK, J. Andrew. O que é missão? Teologia Bíblica de Missão. Londrina: descoberta, 2006.

LÈVY-STRAUSS, Claude. Antropologia strutturale. Trad. Paulo Caruso. Milão: Saggiatore, 1990 , p. 380.

LIDÓRIO, Ronaldo. O desafio do preparo missionário em um contexto de prejuízo histórico. 2003. In Ronaldo \& Rossana Lidório. Disponível em: $<$ http://www.ronaldo.lidorio.com.br/index2.php?option=com_content\&do_pdf=1\&id=19>. Acesso em: 14/11/2015.

MCGRATH, Alister E. Teologia sistemática, histórica e filosófica - uma introdução à teologia cristã. Tradução: Marisa de Siqueira Lopes. São Paulo: Shedd Publicações, 2005 (1953).

REIMER, Johannes. Abraçando o mundo. Teologia de implantação de igrejas relevantes para a sociedade. Curitiba: Esperança, 2011.

RICOEUR, Paul. Na escola da Fenomenologia. Tradução: Ephraim Ferreira Alves. Petrópolis: Vozes, 2009.

ROGERS, Carl R. Tornar-se pessoa. Trad. Manoel José Ferreira. 5.ed. São Paulo: Martins Fontes, 1981.

SILVA, Jarbas F. Tropeços na ação missionária. Londrina: descoberta, 2011.

SCHUTZ, Alfred. Sobre Fenomenologia e Relações sociais. Helmut T.R. Wagner (Ed.; org.). Tradução: Raquel Weiss. Petrópolis: Vozes, 2012.

STEIN, Edith. L'Empatia. Traduzione italiana Michele Nicoletti. 2.ed. Milano: Franco Angeli, 1992.

TILLICH, Paul. Perspectivas da teologia protestante nos séculos XIX e XX. Tradução: Jaci Maraschin. 2. ed. São Paulo: Aste, 1999.

Leopoldo: Sinodal, 2011.

Teologia Sistemática. Tradução: Getúlio Bertelli e Geraldo Korndörfer. 6. ed. São

VAN DER LEEUW, Gerardus. Fenomenologia de la religión. México: Fondo de Cultura Economica, 1964.

WAGNER, Helmut. Introdução. In Sobre Fenomenologia e Relações sociais - Alfred Schutz. Ed. Helmut T. R. Wagner (org). Petrópolis: Vozes, 2012. 